\section{Case Reports in Ophthalmology}

Case Rep Ophthalmol 2016;7:308-314

DOI: $10.1159 / 000452858$
Published online: December 28, 2016

(C) 2016 The Author(s)

Published by S. Karger AG, Basel www.karger.com/cop

This article is licensed under the Creative Commons Attribution-NonCommercial 4.0 International License (CC BY-NC) (http://www.karger.com/Services/OpenAccessLicense). Usage and distribution for commercial purposes requires written permission.

\title{
Reconstructive Surgery of the Upper Eyelid Using the Residual Tarsus after Excision of Sebaceous Gland Carcinoma
}

\author{
Tatsuya Yunoki Yasuhisa Nakamura Chiharu Fuchizawa \\ Atsushi Hayashi \\ Department of Ophthalmology, Graduate School of Medicine and Pharmaceutical \\ Sciences, University of Toyama, Toyama, Japan
}

\section{Keywords}

Sebaceous gland carcinoma - Reconstructive surgery · Residual tarsus · Upper eyelid

\begin{abstract}
Purpose: To report a successful eyelid reconstruction performed using the residual tarsus after excision of a sebaceous gland carcinoma. Case Report: An 86-year-old woman presented with a sebaceous gland carcinoma of the upper eyelid margin. After excision of the tumor, she underwent reconstructive surgery of the superior eyelid performed using the residual tarsus. Because the tumor was localized on the upper lid margin, a tarsus of about 4-5 $\mathrm{mm}$ in height remained after the excision; we therefore used the residual tarsus to reconstruct the upper eyelid. No functional or cosmetic problems arose as a result of this method. Conclusions: Reconstructive surgery of the upper eyelid using the residual tarsus may be a viable option provided that surgeons can ensure a sufficient safety margin, and that more than $4 \mathrm{~mm}$ of the tarsus remains.




\section{Case Reports in Ophthalmology}

\section{Introduction}

Sebaceous gland carcinoma is a typical malignant eyelid tumor that is relatively common in Japan and Asian countries, where it comprises about 30\% of malignant eyelid tumors [1]. The principle treatment for sebaceous gland carcinoma is surgical excision of the tumor - including a safety margin - and reconstruction of the eyelid. Several methods of eyelid reconstruction are used, and these are mainly selected on the basis of the size and position of the tumor.

Reconstruction must be both functional and cosmetic. In particular, when simple reefing is impossible, the anterior and posterior lid lamella must be reconstructed [2-5]. The Hughes flap, switch flap, free tarsus, palatal mucosa, cartilago auriculae, etc. are often used as materials to reconstruct the posterior lid lamella. However, when using the Hughes flap, switch flap, and free tarsus, surgeons must incise the normal eyelid, while use of the palatal mucosa and cartilago auriculae can cause corneal epithelial damage and transformation of reconstructive materials [2-5]. In this case report, we examine the effectiveness of a residual tarsus graft in an upper eyelid reconstruction following excision of a sebaceous gland carcinoma.

\section{Case Report}

An 86-year-old woman presented at another hospital with an upper eyelid mass in the left eye. Because a malignant tumor was suspected, she was referred to Toyama University Hospital for further evaluation. The woman had an upper eyelid tumor $2 \mathrm{~mm}$ high and $5 \mathrm{~mm}$ wide. It was yellowish, had an irregular margin, and was localized inside the upper lid margin (Fig. 1).

We excised the tumor with the patient under general anesthesia. The surgical excision margins were marked, leaving $4 \mathrm{~mm}$ of intact tissue as a safety margin around the tumor border. Sebaceous gland carcinoma was diagnosed using intraoperative frozen sectioning; no malignant cells were found at the edges of the excised tissue. In addition, the tumor or the surgical defect did not include the canalicular system.

Because the tumor was localized on the upper lid margin, a tarsus of about 4-5 mm in height remained after the excision (Fig. 2a); we therefore attempted to pull the residual tarsus downward to the lid margin. To this end, the skin, orbicularis oculi muscle, levator palpebrae muscle, and Muller's muscle were isolated from the residual conjunctival tarsus, and we made a composite graft using the residual conjunctival tarsus (Fig. 2b). Next, both sides of the residual conjunctival tarsus were incised vertically, and it was pulled to the upper eyelid margin (Fig. 2c). The residual conjunctival tarsus was then sewn to the tarsus using 60 polypropylene (Fig. 2d). Finally, the subcutaneous tissue was peeled from the orbicularis oculi muscle, and the skin was pulled to the upper eyelid margin (Fig. 2e). The skin was sewn to the tarsus margin using 7-0 polypropylene (Fig. 2f). The procedures conformed to the tenets of the World Medical Association's Declaration of Helsinki. Written informed consent was obtained from the patient after provision of sufficient information about the procedures.

One week after surgery, we pulled the polypropylene, which had been used to tie the upper eyelid to prevent its rolling, downward (Fig. 2g). Later, a final diagnosis of sebaceous gland carcinoma was made using pathological examination. No functional problems were observed from short-term follow-up to 1 year after surgery (entropion, blepharoptosis, or lagophthalmos) (Fig. 3a, b), and the height of the reconstructive tarsus was about $5 \mathrm{~mm}$ (Fig. 
Case Reports in
Ophthalmology

Case Rep Ophthalmol 2016;7:308-314 DOI: $10.1159 / 000452858$

C 2016 The Author(s). Published by S. Karger AG, Basel www.karger.com/cop

Yunoki et al:: Reconstructive Surgery of the Upper Eyelid Using the Residual Tarsus after Excision of Sebaceous Gland Carcinoma

3c, d). Further, no ocular surface problems were observed, such as dry eye or keratitis, from short-term follow-up to 1 year after surgery (Fig. 3e). A year later, the sebaceous gland carcinoma had not recurred; we considered this a good outcome, i.e. no recurrence of tumor and no functional or cosmetic problems of the eyelid.

\section{Discussion}

Sebaceous gland carcinoma, which arises from the sebaceous gland of the eyelid, is associated with poor prognosis, and it has been reported that local recurrence and lymph node metastases are frequent [6]. For this reason, the tumor must be excised along with a sufficient safety margin. In cases where this margin is $3-5 \mathrm{~mm}$ in diameter, a large eyelid defect occurs, and reconstruction of the eyelid is necessary.

In this study, a large horizontal defect of the upper eyelid occurred; we were nonetheless able to preserve about 4-5 mm of the tarsus vertically. Accordingly, we reconstructed the upper eyelid using the residual tarsus. In general, large defects of the upper eyelid require a skin graft and dermal flap, by which the anterior lobe is reconstructed, as well as a free tarsal graft, palatal mucosa, and cartilago auriculae to enable reconstruction of the posterior lobe [2-5]. However, these procedures can give rise to many potential problems, such as dry eye, corneal disorder, and contraction of the graft $[7,8]$. Using the residual tarsus, no functional or cosmetic problems were observed in the short-term and long-term follow-up after the surgery.

It has been estimated that the tarsus height in the upper eyelid is about $8 \mathrm{~mm}$ in Japanese people [9], and that it is possible to prevent postoperative upper eyelid transformation if a tarsus of about $4 \mathrm{~mm}$ in height is preserved [10]. In this study, the tarsus was pulled downward for a week to prevent rolling of the upper eyelid upward. This method had led to no complications at 1 year after surgery, and thus could provide an approach for avoiding complications in the future. We will continue to monitor this patient for local recurrence or metastasis over the long-term.

In conclusion, reconstructive surgery of the upper eyelid using the residual tarsus may be a viable treatment option if surgeons can ensure a sufficient safety margin and preserve a tarsus of about $4 \mathrm{~mm}$ in height.

\section{Statement of Ethics}

Written informed consent was obtained from the patient for publication of this case report and any accompanying images.

\section{Disclosure Statement}

The authors declare that there is no conflict of interest regarding the publication of this paper. 
Yunoki et al.: Reconstructive Surgery of the Upper Eyelid Using the Residual Tarsus after Excision of Sebaceous Gland Carcinoma

\section{References}

1 Takamura H, Yamashita H: Clinicopathological analysis of malignant eyelid tumor cases at Yamagata university hospital: statistical comparison of tumor incidence in Japan and in other countries. Jpn J Ophthalmol 2005;49:349-354.

-2 Mauriello JA Jr, Antonacci R: Single tarsoconjunctival flap (lower eyelid) for upper eyelid reconstruction ("reverse" modified Hughes procedure). Ophthalmic Surg 1994;25:374-378.

3 Stafanous SN: The switch flap in eyelid reconstruction. Orbit 2007;26:255-262.

4 Leibovitch I, Malhotra R, Selva D: Hard palate and free tarsal grafts as posterior lamella substitutes in upper lid surgery. Ophthalmology 2006;113:489-496.

-5 Kakizaki H, Zako M, Iwaki M: Lower eyelid lengthening surgery targeting the posterior layer of the lower eyelid retractors via a transcutaneous approach. Clin Ophthalmol 2007;1:141-147.

6 Shields JA, Demirci H, Marr BP, Eagle RC Jr, Shields CL: Sebaceous carcinoma of the eyelids: personal experience with 60 cases. Ophthalmology 2004;111:2151-2157.

7 Leibovitch I, Malhotra R, Selva D: Hard palate and free tarsal grafts as posterior lamella substitutes in upper lid surgery. Ophthalmology 2006;113:489-496.

8 Lelli GJ Jr, Lisman RD: Blepharoplasty complications. Plast Reconstr Surg 2010;125:1007-1017.

-9 Goold LA, Casson RJ, Selva D, Kakizaki H: Tarsal height. Ophthalmology 2009;116:1831-1831.

10 Pollock WJ, Colon GA, Ryan RF: Reconstruction of the lower eyelid by a different lid-splitting operation: case report. Plast Reconstr Surg 1972;50:184-187. 
Case Reports in
Ophthalmology

Case Rep Ophthalmol 2016;7:308-314

(c) 2016 The Author(s). Published by S. Karger AG, Basel www.karger.com/cop

Yunoki et al.: Reconstructive Surgery of the Upper Eyelid Using the Residual Tarsus after Excision of Sebaceous Gland Carcinoma
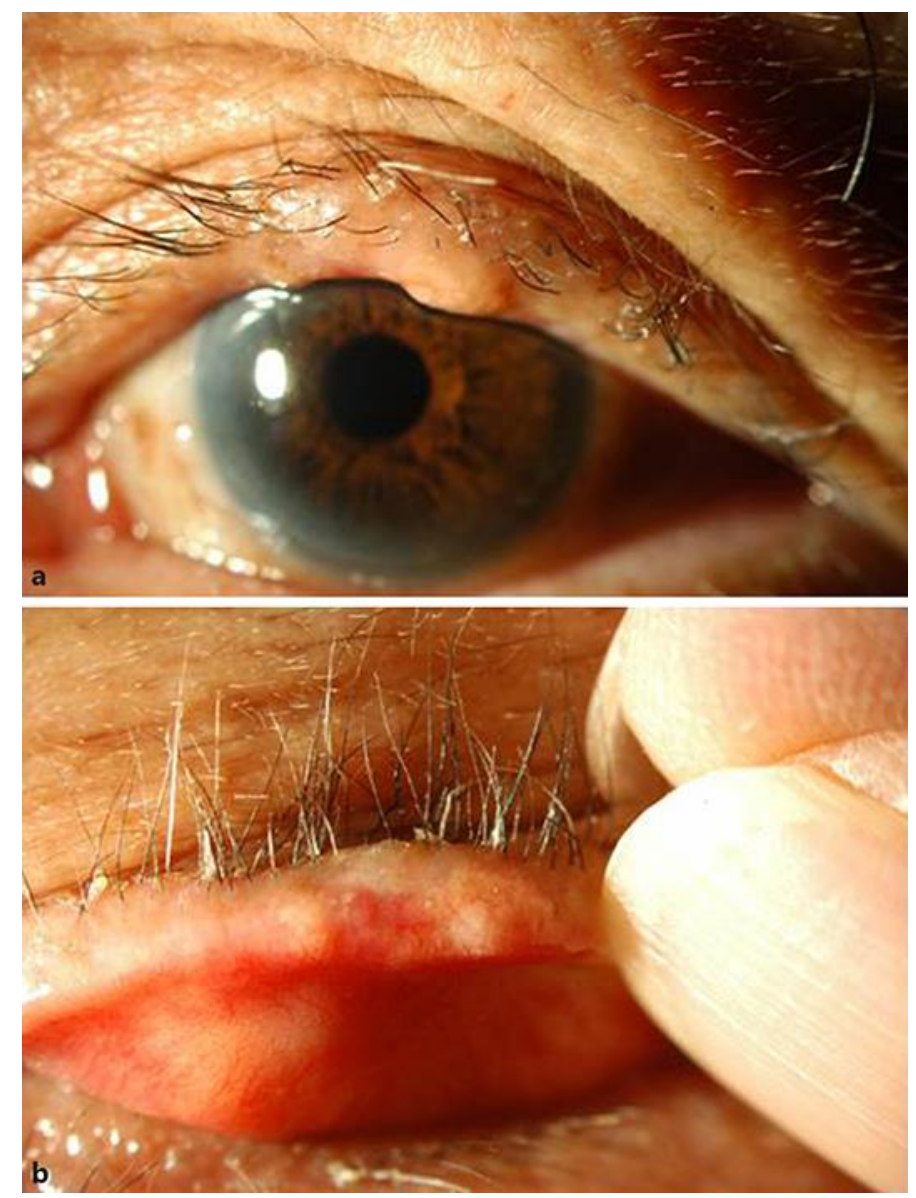

Fig. 1. Sebaceous gland carcinoma of the upper eyelid. a Skin side of the eyelid. b Palpebral conjunctiva side. 


\section{Case Reports in Ophthalmology}
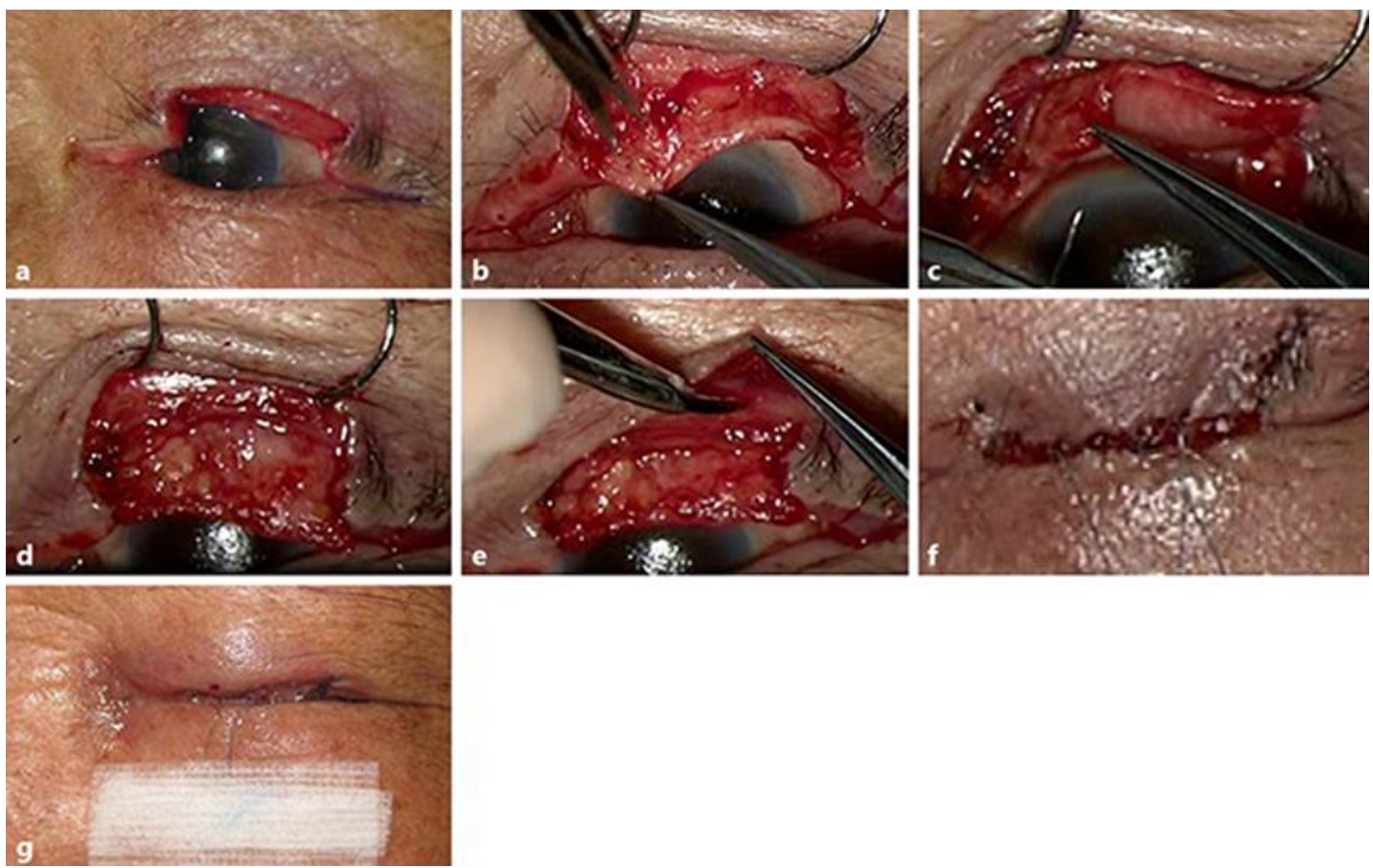

Yunoki et al:: Reconstructive Surgery of the Upper Eyelid Using the Residual Tarsus after Excision of Sebaceous Gland Carcinoma

(C) 2016 The Author(s). Published by S. Karger AG, Basel www.karger.com/cop

Fig. 2. After the excision of sebaceous gland carcinoma. a Defect of the upper eyelid with a safety margin of $4 \mathrm{~mm}$. b-d A composite graft of the residual conjunctival tarsus was made and sewed to the tarsus with 6-0 polypropylene. e, $\mathbf{f}$ The skin was sewed to the tarsus margin with 7-0 polypropylene. $\mathbf{g}$ The day after the reconstructive surgery of the upper eyelid. Traction of the reconstructed upper eyelid using 7-0 polypropylene. 
Case Reports in
Ophthalmology Case Rep Ophthalmol 2016;7:308-314 DOI: $10.1159 / 000452858$

C 2016 The Author(s). Published by S. Karger AG, Basel www.karger.com/cop

Yunoki et al.: Reconstructive Surgery of the Upper Eyelid Using the Residual Tarsus after Excision of Sebaceous Gland Carcinoma
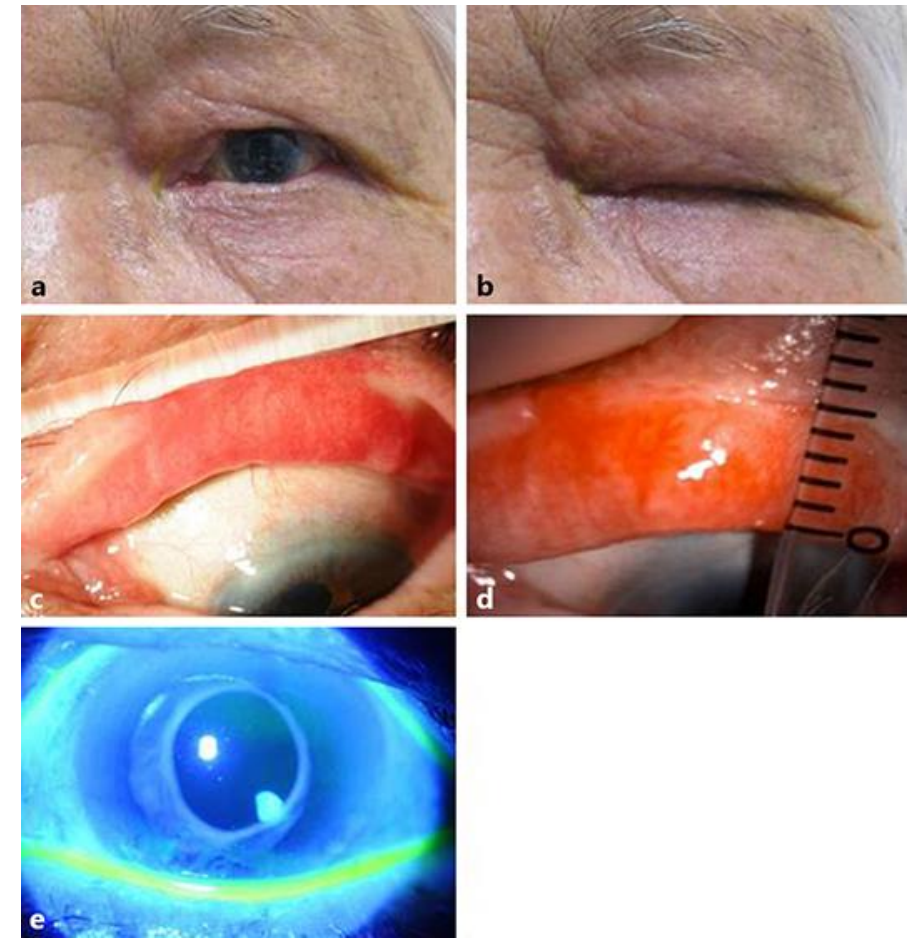

Fig. 3. Results at 1 year after surgery. a Opened eye. b Closed eye. c, $\mathbf{d}$ The height of the tarsus was about 5 $\mathrm{mm}$. e Results of fluorescein eye staining. There were no complications of the ocular surface after surgery. 